\title{
ENGAGING COMPUTER ASSISTED LANGUAGE LEARNING (CALL) IN 2013 NATIONAL EDUCATION CURRICULUM
}

\author{
Endah Januarti \\ SMK Negeri 1 Madiun
}

\begin{abstract}
The implementation of CALL in the classroom to improve the students' reading capability is successful viewed from some dimensions. The implementation of CALL in the classroom can change the role of students and teacher in classroom interaction; from teacher-centered to studentscentered which makes the students be the central of the instructional process. CALL also improves the process of learning. It motivates the students to learn, provides various teaching materials, and triggers the students' creativity by providing nearly unlimited learning materials. However, in integrating the application into the curriculum the teacher need to make the application meaningful for the students. For this, the function of the computer is to support the learning objectives. The implementation of CALL in the classroom is very essential in enhancing the students' capability in English language learning. Therefore, it is recommended that; (1) English teachers should pave the way the development of technology to improve their quality of teaching; (2) English teacher need to be creative and innovative in developing learning strategies to create better learning environments; (3) Schools have to provide the students better facilities; and (4) Due to the limited time to study at school, it is recommended for the students to study after class since CALL provides them opportunities to develop themselves to improve their language competence, especially reading.
\end{abstract}

Key words: CALL, 2013 National Education Curriculum

\section{Introduction}

A curriculum is an extensive plan of teaching and learning that guides students to interact with instructional content, materials, resources, and processes for the attainment of educational objectives. Although curriculum is

The future of a nation depends on its curriculum. The former President Susilo Bambang Yudhoyono stated that education should not only make people smart but also to train Indonesians to be mentally tough, physically healty, tolerant, and willing to live in harmony with others in different religions, race, and tribes. In order to achive the national education target, government launched a new an essential element in determining the education quality, there are other factors to consider, namely, teachers' professionalism, supporting society, environment, and media. Those will determine the education quality. national education curriculum in 2013 which is then popular with 2013 National Education Curriculum.

This new curriculum bring about changes in time and approach. It is worth noting that 2013 Curriculum innovates the approach by implementing scientific approach which can be implemented through problembased learning, discovery learning, project- 
based learning as well as co-operative learning. Unfortunately, the changing of time give an impact on English language learning. The very limited time ( $2 \times 45^{\prime}$ per week) makes teachers feel burdened to reach the target, since they have to cover the four basic skills of language learning, namely listening, speaking, reading, and writing. Teachers need to give to students up-to-date theories and models which describe processes of literacy from various viewpoints, as well as approaches and models for developing language skill.

On the other hand, many students complaint on their low academic achievement. At least there are two major factors underlying this problem. First, factor of learners' different personalities, learning, response pace, motivation, and language proficiency result in individual inequality to participate in class or in group. For example, learners who are shy, slow, or afraid of making errors may choose to participate less in the classroom or group discussions. The second factor is what-a-socalled environment factor. Students do not have the need to use the target language outside the classroom. The only chance for them to use the language is in the classroom.

This is in line with what Chambell (in EFL journal, 2004) stated that unlike ESL learners who need to use the target language in everyday life for surviving in the target culture, EFL learners generally do not have adequate access to the target language outside the classrooms and practice what they have learned in the classroom. Learners normally return to the real world speaking their mother tongue as soon as they leave the classroom.

Students also feel that the lesson is performed uninterestingly. They are trapped into a tradition that language learning is to have a paper, read the text and answer questions. These routine activities make the students come into unmotivating condition which leads the students to become unmotivated learners.

The above conditions result in students' low participation, motivation, and encouragement.

As the students become more advance, engaging them in the learning process and the language they are going to learn becomes a necessity to avoid boredom and maintain learners attentiveness and motivation in the language classes. Teachers need to know how to respond to the challenges of the knowledge society and how to prepare their pupils to be autonomous life-long learners.

The ongoing global restructuring of work life requires important new skills such as flexibility in thinking, continuous learning, participation in multicultural work settings, responsible team work, taking initiative, and the use of information and communication technology.

By-so-doing the use of information technology and multimedia in language teaching is becoming important. Efforts to make use the development of technology in language teaching have been made to enhance 
students' performance in EFL and computers which are widely used in many sectors are considered to be one of the promising teaching media in language teaching.

However, teachers' creativity plays an important role in the success of language learning activity. Warschauer (in ELT journal, 2006) states that the key to successful use of technology in language teaching lies not in hardware or software but in humanware- our human capacity as teachers to plan, design, and implement effective educational activity. Language learning is an act of creativity, imagination, exploration, expression, construction and profound social and cultural collaboration. If we use computer to fully humanize and enhance this act, rather than to try to automate it, we can help bring out the best that human and machine have to offer.

Many problems raise up to question about the implication of computers for

\section{The Nature of Curriculum}

Many scientists provide different definition on curriculum. Skilbeck (1984) states that a curriculum is a framework for the enhancement and organization of the varied and numerous experiences of students in a school setting and beyond the school. While Rogers and Taylor (1998), define a curriculum as all the learning that is planned and guided by training or teaching organizations. The training could be carried out in groups, or individually, inside or outside a classroom, in language learning. At which stage of lesson computers can be used? And for what purposes? How should the process of learning be a process of using English for communication? Therefore, how to design effective communicative task to overcome the problem of students' low motivation and the failure of achieving the required score in English language learning is becoming a key issue. For this reason, the implementation of Computer Assisted Language Learning (CALL) in language learning will help teachers select, adapt or create their own design of effective communicative tasks to improve the quality of their teaching. CALL also answers the problem on the limited time in classroom activities as it can be easily accessed by everyone, everywhere, and everytime.

an institutional setting, or in the field. According to Jarlind (1998), a curriculum also assists in monitoring teaching and learning processes. It will be noted that whereas the wording is different, the general message is that a curriculum is a framework for planned /organized teaching and learning for either groups or individuals, within or without an institutional setting to achieve stated objectives. 
The Implementation of 2013 National Curriculum

Responding to the era of globalization, every country must prepare and empower its resources without delay. Otherwise they will be lagging behind. For this reason, the Direktorat Pembinaan Sekolah Menengah Kejuruan as a sub-system of the national development and management system, urgently sets about to empower all its resources, especially toward the raising of the capability of school students so that they can compete effectively with others. Students must be equipped with globally recognized tools to make them more acceptable, competitive and upgradeable in accordance with the world demand.

Considering those reasons, government launched a new national curriculum in 2013 which has met unlikely opponents; confused teachers who doubt that they are ready for the upcoming learning instructions. The very reason to justify such implementation of new curriculum is because the government wants to restore character education and improve students' creative thinking. Under this curriculum the former Education Minister, M. Nuh, claimed at least three benefits. First, this curriculum determines the passing competences standard (SKL). Second. It also offers the continuously-related competences on all level of grades. Third, it uses a more holistic approach for the learning process based on students' creativities. The 2013
Curriculum makes a change in the approach by implementing scientific approach which can be implemented through problem-based learning, discovery learning, project-based learning as well as co-operative learning.

\section{Computer-Assisted Language Learning}

(CALL)

\section{The Nature of CALL}

A definition of CALL that accommodates its changing nature is any process in which a learner uses a computer and, as a result, improves his or her language (Beatty, 2003: 7). CALL is closely related to many other discipline and the computers function as tools to aid or study.

Teachers can use the computer as an aid to managing language classroom activities; it has a multitude of roles to play in the curriculum, ranging from tutor to students' tool. It should be noted that this concerns itself with the use of computers at a language school, supported by a teacher (Stern, 2002: 15). To make informed choices, teachers need to be familiar with the various computer applications; games, simulations, tutorials, problem-solving programs, word processing, graphic tools, and integrated learning system (Molenda et al., 2005: 109).

Beatty (2003: 2) states that CALL is a young branch of applied linguistics and is still establishing its directions. Therefore, it will keep us updated and regularly re-informed about the adoption of existing technologies. The field of CALL is also constantly 
undergoing change because of technological innovation that creates opportunities to revisit old findings, to conduct new research and to challenge establish beliefs about the ways in which teaching and learning can be carried out both with and without a human teacher(Beatty, 2003: 1). Moreover, Beatty said:

CALL is employed in many ways, both in and out of the classroom. In some commercial application meant to be used by individuals away from the home. CALL is promoted as a complete method of learning a language. In the classroom it can be used both as a reward for better learners or a remedial aid for weaker ones.

\section{Phases of CALL}

Computer Assisted language learning has gradually developed since 1950s and classified into three main phases. The phases are defined as behaviorist CALL, communicative CALL, and, the most recently, integrative CALL. The introduction of a new phase does not necessarily entail rejecting the programs and methods of a previous phase. As what Markwaschauer (in ELT Journal vol.6, 2006: 8) states that the phases do not gain prominence one fell swoop, but, like all innovations, gain acceptance slowly and unevenly. Rather the old is subsumed within the new.

\section{a. Behavioristic CALL}

The rationale for the CALL programs developed at this time were: 1) repeated exposure to the same material is beneficial or even essential to learning; 2) a computer is ideal for carrying out repeated drills, since the machine does not get bored with presenting the same material and since it can provide immediate non-judgmental feedback; and 3) a computer can present such material on an individualized basis, allowing students to proceed at their own pace and freeing up class time for other activities

However, Wyatt (in Stern, 2002: 20) states it was not long before a number of problems were identified: 1) Materials are presented in a highly-structured, predetermined manner; 2) Students are passive responders, not initiators; 3) The computer functions as an authoritative instructor; 4) Learning paths are predetermined; and 5) The computer instructs the students; the students learn from the computer.

b. Communicative CALL

The appearance of new language learning theories and approaches, particularly Communicative Language Teaching, helped produce a new approach to CALL, Communicative CALL. This new approach uses the same software as the previous one. The major differences are in the way the software is used. The features of communicative CALL are that it: 1) focuses more on using forms rather than on the forms themselves; 2) teaches grammar implicitly rather than explicitly; 3) allows and encourages students to generate original utterances rather than just manipulate prefabricated language; 4) does not judge and 
evaluate everything the students do nor reward them with congratulatory messages, lights, or bells; 5) avoids telling students they are wrong and is flexible to a variety of students' responses; 6) uses the target language exclusively and creates an environment in which using the target language feels natural, both on and off the screen; and 7) will never try to do anything that a book can do just as well ( Mark Warschauer in Stern: 2002).

\section{c. Integrative CALL}

More developments in other areas of learning theory and in technology promoted the appearance of this phase. This involves the use of multimedia, and the Internet. Warschauer (in ELT Journal vol.6: 2006) defines this category as allowing a variety of media to be accessed on the one machine. In this approach, computer skills are not taught separately from other subjects, but incorporated into the regular curriculum where they support the learning objectives.

Lockard and Abrams (in Stern, 2002: 38) describe the advantages of the integration: 1) There is an emphasis on curriculum rather than technology; 2) Existing objectives are enhanced with computer applications; 3) The computer becomes the teacher's partner, not a competitor; and 4) The computer is treated in a natural way, as one fundamental tool for learning and living.

Mark Warschauer (in ELT journal, 2006: 8) states that research indicates that computers are most effective when they are "an integral component of a new way of learning and working, instead of being used in an isolated fashion". However, the effective integration of information skills has two requirements: 1) the skills must directly relate to the content area curriculum and to classroom assignments, and 2) the skills themselves need to be tied together in a logical and systematic information process model (Eisenberg and Johnson in Stern, 2002: 39).

Computer Assisted Language Learning has provided a different teaching paradigm of the role of reading in the language classroom. CALL offers hypertext and hyper-media to overcome the problems of limited teaching materials faced by the teachers as well as the students. The teacher has nearly unlimited sources and a chance to select the type of text that can be used in instructional process. When the goal of instruction is communicative competence, everyday materials such as train schedules, newspaper articles, and travel and tourism web sites become appropriate classroom materials, because reading them is one way communicative competence is developed.

Previous research showed that CALL was proved to be effective in building students' motivation. As the result of his study O’ Donnell (2006) states:

For success, the outline provided by Jonassen (1998) for good coaching should certainly accompany CALL: motivate, analyze, provide feedback and advice, and persuade learners to 
assess their performance critically. Multimedia can provide access to numerous aspects of language such as mannerisms, tone of voice and other human behaviors that are much more readily adopted through exemplars than through description. Therefore, by providing many sources of information it should lead to a more readily learned and in-depth understanding of certain linguistic concept.

Engaging the students in the development of technology will promote their language performance. The integration of computer into English Language Teaching can increase both input (exposure) and output (use) of the target language that is needed for learners to promote both their linguistic and pragmatic competence.

CALL which is applied through Task-Based Language Teaching in the form of Project or Problem- Based Learning fit well with technology-rich learning environments where the focus is not on the hardware and software, but on the learning experience. In each case, technology is used to facilitate learning. It may be a tool to organize idea (such as inspiration), search for current information (such as an on-line news source), or present ideas (such as Power Point presentation). However, the focus of learning environment is the students' excitement about solving a problem or addressing an issue they find meaningful.

\section{Implementing CALL in 2013 National Education Curriculum}

The role of Teachers and Students in 2013 National Education Curriculum

The 2013 National Education curriculum requires teacher to provide the students an opportunity for self-assessment and continuous improvement. By so doing, the teacher should be able to motivate them to independently search for more knowledge. For this reason, CALL can be applied and fit well in 2013 national education curriculum, since; (1) Computer provides hypertext and hypermedia which can be accessed by the students anywhere and anytime. It can be used to solve the problem of the lack of instructional materials and the limited time to study; (2) Computer presents various techniques in presenting the material. It can be in the form of games, simulations, projects, and some others, which can be used to overcome the problem of monotonous activities; (3) Browsing in the internet, the students will get exposed with the materials easily and quickly to sharpen their knowledge about the target language to prepare themselves for the real usage.

Meanwhile, this new curriculum sets the students as constructivists. They have to develop themselves through some experiments. They have also to be able to develop their creativity and problem solving strategy, expose to the language through examples or illustrations, observe and analize the language through guided questions given by the teacher. As a matter of fact, the 
implementation of CALL is one way to overcome the problem of the students' limited exposure to the target language since they could find much information about the authentic learning materials they needed to support their achievement. Due to their lack of students' book this was a proof that computer with its internet access could function as their students' book containing nearly unlimited sources to help the students to improve optimally.

The result of the application of CALL proves that it could improve students' motivation in language learning. It could change the students' paradigm that learning language was simply having a piece of paper, reading the texts, and answering the questions by providing them motivating, challenging, and encouraging tasks.

By so doing the role of the teacher changes as what it is required in 2013 National Education Curriculum. She performs as consultant and facilitator rather than "Mrs.know-all". Therefore, the instructional process shifts from teacher-centered to studentcentered. As a result, teacher does not dominate the activities in the classroom but guide the students to develop optimally by making use the computer as the teaching media. Moreover, computer with its hypertext and hypermedia helps the students to solve the problem of lack of materials. The students could find the material in the internet as many as possible. Working with computer also improves the students' self-responsibility for each student has his own responsibility to finish the task given by the teacher.

Moreover, the implementation of CALL in the classroom together with the appropriate task given by the teacher could stimulate the students' creativity. CALL allows the students to relate their new concept being intrduced to the previous knowledge. This will stimulate the students to create thier own products, as a result, it will develop a sense of self-esteem and ownership for the students' work. A study shows that when the students were asked by the teacher to design an advertisement on a certain product, the Audi A6 2.0 TDI Limited Edition. It was very surprising when the students with their own creativity were able to design beautiful and attractive advertisement. Even they gave a compliment to each other. This spirit shows that CALL can be well engaged in 2013 National Education Curriculum.

In term of comprehending the text, CALL influences much on students' better understanding of the text, since this activity was a kind of working memory activation which stimulates their brain to link between what the language is and what they can do with the language. It covers the improvement of language competence in terms of constructing words into sentences and finding errors in the sentences, the improvement of comprehending texts, and the improvement of the instructional process. The students learn 
how to construct words into sentences by combining sentences they got from the texts which are written in the authentic language they browse in the internet. They could memorize the pattern and try to apply it in finishing their task. To the students, it is a habit formation.

Through implementation of CALL in the classroom, the students realize that activity they do in the classroom is meaningful. The students are triggered to be more creative and innovative by making use of the facilities they can find in their computer to solve the task given by the teacher. It also enables the students to save the time since the students could simply pick up the picture from the computer and put them as they like without any activity of drawing. By so doing, the students are able to finish their work on time.

The Example of Implementing CALL in the Instructional Process

Subject

Class/Semester

Material

intention

Time Allotment $: 2 \mathrm{x} 45$

$: \mathrm{X} / 1$
: English

: $\quad$ Expressing

A. Learning material

1. Social Function of the text

- Expressing intention

2. Structure of the text

- Main idea ofthe text

- Using be going to to express intention
3. Language function

- (Verb) used in the expression :

- I'm going to $+V 1+C$

- Grammar, pronounciation stress, intonasi, spelling, and punctuation

B.Learning Method/Approach

1. Approach : Scientific approach

2. Model : Discovery learning

3. Technique : Presentation, CALL

C. Media, Instrument, and Learning Sources

1. Media : Picture

2. Instrument : Laptop, white-board, LCD

3. Learning sources

Students' book

http://busyteacher.org/19600-going-tofuture-plans.html, http://busyteacher.org/17006-going-toplans-and-intentions-worksheet.html www.dailyenglish.com,

\section{$\underline{\text { http://americanenglish.state.gov/files/ae/resour }}$} ce files,

http://learnenglish.britishcouncil.org/en/,

D. Learning Scenario

Meeting 1

1) Warming Up (10’)

- Greeting and having a prayer

- Checking attendance

- Checking the students readiness to follow classroom activities physically and psychologically

- Reviewing 
- Doing a kind of brainstroming related to the topic which are going to be discussed by questioning the students as follows:

- What are you going to do in the rest time today?

- Mentioning the instructional objectives and the competency standart

(Based on my question previously, Now, please guess! what topic are we going to discuss today?)

- Mentioning the target they are going to achieve and why it is worth-doing

- Explaining the course-outline and the activity they are going to do to finish the task..

2) Core Activity

\section{Observing (Stimulation) (5')}

- Showing pictures of some tourist destinations on a slide and ask the students to observe. (Look at the pictures. Do you know these places? Why do you think people visit these places? What do they do there? Which one do you prefer to visit? Why? Discuss it with your friends.)
- Picture 1.1. Beach

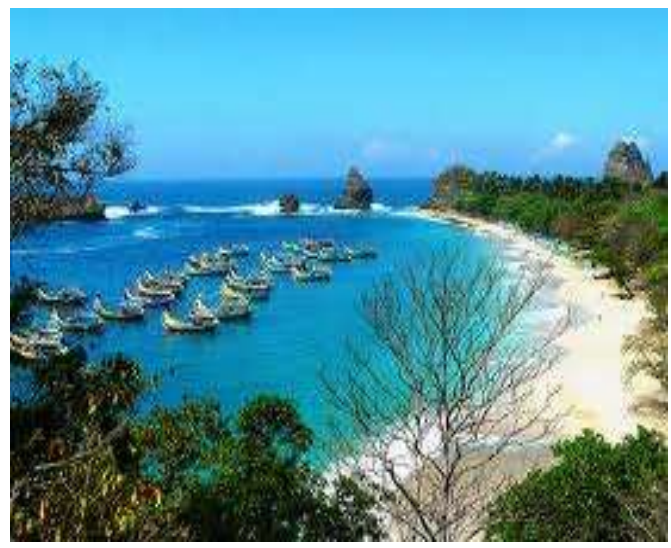

Picture 1.2. Amusement Park

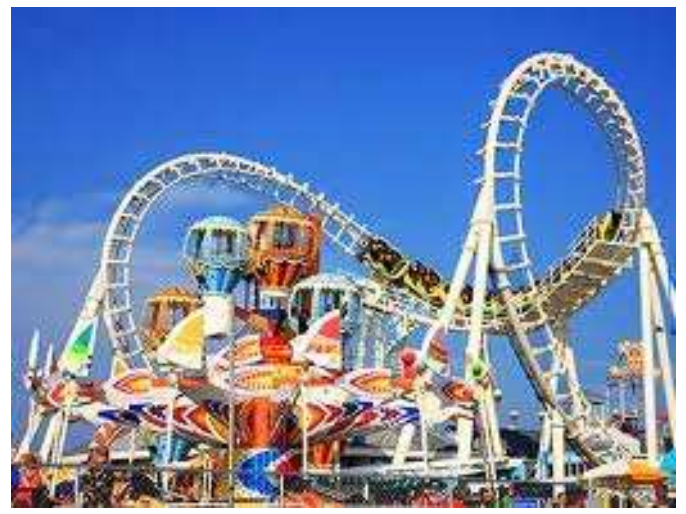

Picture 1.3. Mall

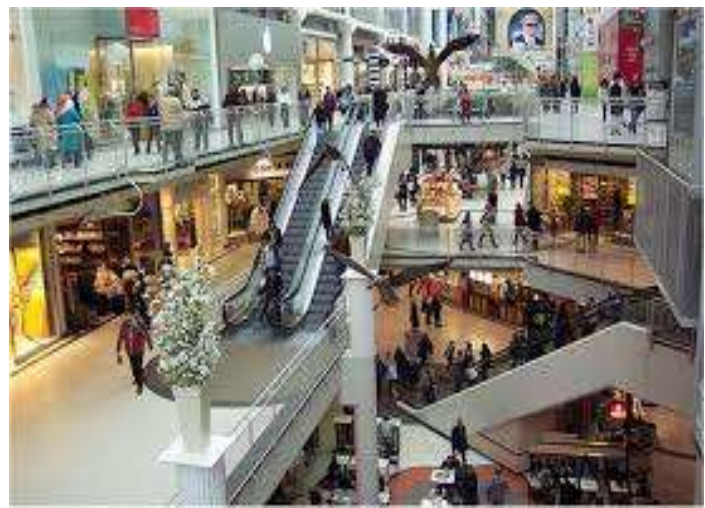

Picture 1.4. Mountain 


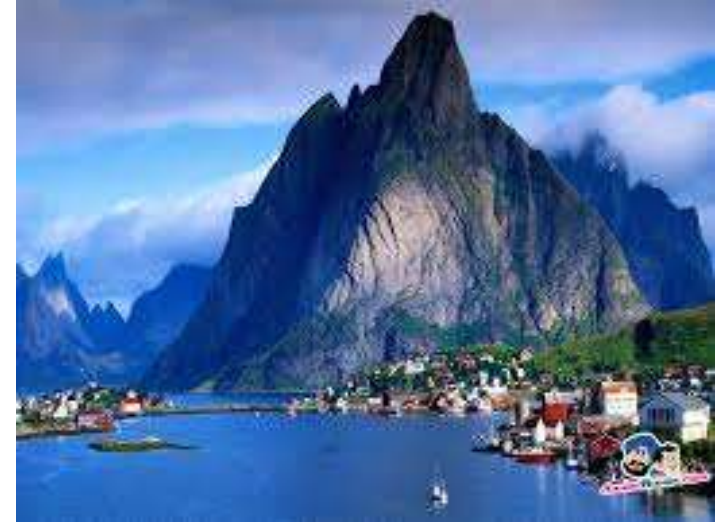

\section{Questioning (Problem Statement)} (15')

- Asking the students to read the text on holiday plan

- Under the teacher's guidance, the students are supposed to question the main idea of the text and identify the expression of intention. (After you read the text, what are the questions you have in your mind in term of the content and the language?)

\section{Exploring (Data Collection) (10')}

- Asking the students to work in a group of five

- Showing a slide containing a jumbled dialog

- Asking the studenta to arrange the jumbled dialog into a good/correct order

\section{Dialog:}

Santi : It will be a long holiday soon. Do you have any plan?
Bayu : Definitely! My dad and I am going to go fishing.

Santi : Fishing? I don't really like fishing. I would rather stay at home than go fishing.

Bayu : What about you Riri? What would you like to do on the long holiday?

Riri : I have made a plan with my mother about what to do on this long holiday. We are going to practice baking cookies.

Santi : That sounds like a very good plan!

- Discuss the result of the group work

- Asking the students to act out the dialog.

\section{Associating (Data Processing) (20')}

- Asking the students to identify and analyze the grammar used in the dialog

- Asking the students to explain the sentence pattern used in expressing intention (future tense)

- Asking the students to build sentences based on the pattern

- Asking the students to write down the sentence on the board.

- Discuss the result of the work with the class 
- Giving feed-back to students

- Asking the students to revise their work (if it should be corrected)

\section{Communicating (Verification) (25')}

- Showing a slide containing some website-addresses

- Asking the students to browse in the internet ( through the given website) and find the place where she/he wants to visit someday

- Asking the students to write down their holiday plan individually

- Asking the students to exchange their paper and provide feed-back to their friend's work

- Asking the students to submit their paper

- Providing feed-back to the students' work

3) Closing

\section{Reflection (Generalization) (5')}

- Under teacher's guidance, students make a conclusion on what they have learned that day.

- Giving task to students to interview their friend about his/her holiday plan.

From the stages it can be analyzed that the role of the students and teacher changes. The domination of the teacher during the instructional process is reduced. The teacher has a role of the instructional manager rather than presenter. As such she is concerned with managing the computer system and managing the students. On the other hand, the role of the students moves from passive learner to be the central of the instructional process. This is in line with what is stated by Newhouse and Oliver (1989: 88):

In CALL applications the dominant role is played by the students particularly in the student-computer interaction. Therefore the students need to develop a strong sense of responsibility for their own learning and develop skills associate with the management of time, concentration, self-discipline, attention to task and ability to follow instructions.

In accordance with the students' interdependence while they are working in their groups, it is preferable for the teacher to combine this technique with task-based language teaching or cooperative learning which focuses to the implementation of groupwork during the instructional process. There are five principles undermining cooperative learning, namely; (1) positive interdependence, it means that every member of the group realized that they have to work together to achieve the intended goals; (2) face to face interaction; (3) Individual accountability, it means that each member has to study and give contribution toward the success of the team; (4) use of collaborative/ social skills; and (5) group processing in 
which the students have to evaluate how they can do the task effectively.

\section{Conclusion}

CALL can be applied and fil well in 2013 Niational Education Curriculum since it provides nearly all the requirements and the spirits this new curriculum requires to achieve the target. In integrating the application into the 2013 National Education Curriculum, the teacher needs to make the application meaningful for the students, since one of the teacher's roles is to help students interpret their experiences. It can't be argued that the

\section{Bibliography}

Beatty, K (2003) Teaching and Researches, Computer Assisted Language Learning, London: Pearson Education.

Brown, HD (1994) Teaching by Principles, USA: Prentice Hall Regents.

Candlin, CN,(1986) Computer in English Language Teaching and Research, London: Longman.

Duffi, JL et al. (2003) Teaching and Learning with Technology, New York: Pearson education.

Heinich, R et al. (1996) Instructional Media and Technologies for Learning, New Jersey: Prentice Hall Inc.

Newby, TJ et al. (2000) Instructional Technology for Teaching and computer permits a much richer exploration of experience but demands a high level of competence on the part of the teacher to permit students to fully benefit from this experience.

To make sure that the activities are beneficial to students, teachers, and schools, teachers as well as the students should be well equipped with good understanding on how to operate computer. Schools also provide adequate facilities to support the implementation of Computer-Assisted Language Learning by installing LAN and the supporting software.

Learning, New Jersey: Prentice Hall Inc.

Newhouse, P (1989) Teachers Use Computers, A Guide for Teachers, Victoria Park: Napier Publication.

Richard, JC (2001) Curriculum Development in Language Teaching, New York: Cambridge University Press.

Warschauer, Mark(2006)Computer-Assisted Language Learning, http://www.gse.uci.edu/faculty/mark w/call. html. 